Understanding and predicting the temporal variability of sediment grain size characteristics on high-energy beaches

\title{
Prodger, S
}

http://hdl.handle.net/10026.1/4591

10.1016/j.margeo.2016.04.003

Marine Geology

Elsevier BV

All content in PEARL is protected by copyright law. Author manuscripts are made available in accordance with publisher policies. Please cite only the published version using the details provided on the item record or document. In the absence of an open licence (e.g. Creative Commons), permissions for further reuse of content should be sought from the publisher or author. 


\section{Accepted Manuscript}

Understanding and predicting the temporal variability of sediment grain size characteristics on high-energy beaches

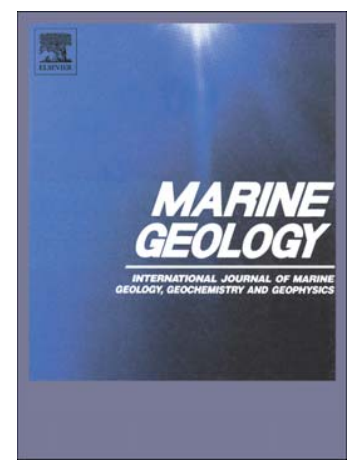

Sam Prodger, Paul Russell, Mark Davidson, Jon Miles, Tim Scott

PII:

S0025-3227(16)30049-4

DOI:

doi: 10.1016/j.margeo.2016.04.003

Reference:

MARGO 5439

To appear in: $\quad$ Marine Geology

Received date: 19 December 2015

Revised date: $\quad 31$ March 2016

Accepted date: 1 April 2016

Please cite this article as: Prodger, Sam, Russell, Paul, Davidson, Mark, Miles, Jon, Scott, Tim, Understanding and predicting the temporal variability of sediment grain size characteristics on high-energy beaches, Marine Geology (2016), doi: 10.1016/j.margeo.2016.04.003

This is a PDF file of an unedited manuscript that has been accepted for publication. As a service to our customers we are providing this early version of the manuscript. The manuscript will undergo copyediting, typesetting, and review of the resulting proof before it is published in its final form. Please note that during the production process errors may be discovered which could affect the content, and all legal disclaimers that apply to the journal pertain. 


\title{
Understanding and predicting the temporal variability of sediment grain size characteristics on high-energy beaches.
}

\author{
Sam Prodger ${ }^{\mathrm{a}}$, Paul Russell ${ }^{\mathrm{a}}$, Mark Davidson ${ }^{\mathrm{a}}$, Jon Miles $^{\mathrm{a}} \& \operatorname{Tim~Scott}^{\mathrm{a}}$ \\ ${ }^{a}$ School of Marine Science \& Engineering, Plymouth University, Plymouth, PL4 8AA. \\ Corresponding Author: sam.prodger@plymouth.ac.uk
}

\begin{abstract}
Despite representing a key parameter when modelling morphology or sediment transport, surface sediments are often assumed homogenous, with grain size temporally constant. This contribution uses a 6-year data set of monthly sediment samples to quantify the observed variability in intertidal beach sands at four energetic, macrotidal locations (North Cornwall, UK). Changes in grain size and sorting were related to periods of high-steepness storm waves promoting a relatively rapid coarsening and an improvement in sorting and low-steepness swell waves a fining and a reduction in sorting. These temporal changes in intertidal grain size were coherently linked to the disequilibrium in wave steepness, with peak coarsening occurring when the instantaneous wave steepness conditions vastly exceeded a temporally evolving antecedent time series. Using this concept, a simple model is proposed that provides skilful predictions of the unseen variability in sediment grain size (average $r^{2}=0.86, p$ $<0.01$ ) and sorting (average $r^{2}=0.75, p<0.05$ ), at all four sites.
\end{abstract}

Keywords: coastal sediments; grain size; beaches; field measurements; modelling

\section{Introduction}

Sandy beaches are abundant worldwide; they provide a natural coastal defence by dissipating high-energy storm waves and are an important socio-economic resource. The coastal zone represents a highly energetic and dynamic environment, where the 
beach slope and morphology continually attempt to reach equilibrium with the changing hydrodynamic conditions. Grain size and sediment sorting are two key textural parameters used to describe beach sands (Folk, 1966). There have been many studies relating these parameters to beach slope (Dean, 1973, Mclean and Kirk, 1969), morphology (Masselink and Short, 1993, Scott et al., 2011) and sediment transport (Masselink et al., 2005, Mclaren and Bowles, 1985). Beach morphology (Baptista et al., 2014, Masselink and Pattiaratchi, 2001), sandbar location (De Santiago et al., 2013, Stokes et al., 2015), aeolian sand dune accumulation (Sherman and Bauer, 1993, Wal and Mcmanus, 1993) and sediment transport pathways (Curran et al., 2015, Larson and Kraus, 1995) have all been shown to be highly variable across a variety of temporal scales. However, studies of the long-term temporal evolution of the sediment characteristics associated with these changes are lacking. Instead, sediments are often assumed to be well sorted and homogenous in both size and composition, with grain sizes remaining fixed in space and time. Additionally, characterisation of sediments is generally based on physical samples that are limited in terms of temporal coverage (Hanson and Kraus, 1989, Nielsen, 2002, Turki et al., 2013).

A number of recent studies have shown there to be significant variations in sediment characteristics across a number of temporal and spatial scales. Holland and Elmore (2008) showed that generalising complexity in terms of simplified descriptions (e.g. a single $\mathrm{D}_{50}$ value, where $\mathrm{D}_{50}$ is the median particle size by mass) was insufficient in capturing the influence of many coastal sediments. Gallagher et al. (2011), presented evidence that large spatial variations in beach face grain size of the order of 0.2-0.7 mm were possible over 10-100 $\mathrm{m}$ and Gujar et al. (2011) found that local and seasonal environmental conditions both produced substantial changes in beach morphology and sediment characteristics. There have also been recent advances in the 
sediment transport modules of models such as Delft3D (Yang et al., 2013) and XBeach (Roelvink et al., 2010), which can simulate some limited short-term temporal changes in sediment properties (Villaret et al., 2013). However, the capability to capture such variations consistently over seasonal/annual time-scales is not currently possible.

This paper investigates the magnitude of the observed temporal variability in sediment characteristics, whether this variability is significant in terms of nearshore morphodynamics and sediment transport and whether the variability is predictable.

\section{Site Descriptions and Data Collection}

Monthly sediment samples have been collected at four (Perranporth, Porthtowan, Chapel Porth and Gwithian) (Figure 1) energetic, macrotidal (mean spring range $6.5 \mathrm{~m}$ ) beaches on the north coast of Cornwall, UK (Scott et al., 2009) since 2008. These beaches all face west / northwest towards the Atlantic Ocean and are exposed to the prevailing westerly winds. Like many beaches that face the open ocean, they therefore receive a wide variety of low steepness swell waves and high steepness wind waves.

With a full spring to neap cycle occurring every two weeks, sampling occurred on the lowest spring low tide for the month, which was deemed sufficient to capture both the short- and long- term variability in sediment grain size. The data presented here are 'surface' samples from the upper $0.02 \mathrm{~m}$ of the sediment column collected at consistent mid-tide positions, located by RTK-GPS, on the linear part of the beach profile, away from the three-dimensional rip and bar topography that is sometimes present towards spring low-tide. Spring high-tide positions were similarly avoided as they receive no wave action on neap tides. Simultaneous monthly topographic surveys were also carried out at the beaches. The sites are all comprised of medium quartz sand with time-averaged median grain sizes $\left(\mathrm{D}_{50}\right)$ over the 6-year study period of $0.33 \mathrm{~mm}$ at 
Perranporth, $0.43 \mathrm{~mm}$ at Chapel Porth, $0.37 \mathrm{~mm}$ at Porthtowan and $0.30 \mathrm{~mm}$ at Gwithian.

The beach morphological classification of each site varies between Low-Tide Bar / Rip and Dissipative (Scott et al., 2011). There is a strong seasonality in incident wave conditions, with average summer and winter significant wave heights of $1.2 \mathrm{~m}$ and 2.7 $\mathrm{m}$ respectively and maximum wave heights exceeding $9 \mathrm{~m}$. Each site is a natural, open coast beach with a shore normal wave approach, where the storm / swell cycle drives cyclic sediment movement in onshore and offshore directions, with no significant net longshore component to the sediment transport (Masselink and Russell, 2006). Each site is backed by Quaternary aeolian sand dunes, composed of quartz sediment that is slightly finer than the intertidal beach sand.

Statistics from the monthly sediment samples were quantified using the settling tube approach of Folk and Ward (1957), with sediment fall velocity converted to median grain size $\left(\mathrm{D}_{50}\right)$ using the Ferguson and Church (2004) method. Each sample was passed through the settling tube on five occasions, with a $\mathrm{D}_{50}$ resulting from the average of these five tests. If the standard deviation of the five runs exceeded $0.01 \mathrm{~mm}$ ( $0.5 \%$ of sample size) then the analysis was repeated until the standard deviation was less than $0.01 \mathrm{~mm}$.

Monthly data is available from 2008 to 2014 for Perranporth and Porthtowan and 2008 to 2010 for Chapel Porth and Gwithian, with 485 separate grain size samples collected by hand during 207 separate field visits. Sampling frequency was increased to bi-monthly between December 2013 and February 2014 in order to capture the variation caused by a number of extreme storms.

Samples were collected from the same mid-tide position (+/- $0.5 \mathrm{~m}$ horizontally) each visit, identified using an RTK-GPS. Significant wave height $\left(H_{s}\right)$, peak period 
$\left(T_{p}\right)$ and direction were recorded every 30 minutes from a nearshore wavebouy $\left(50.35379^{\circ} \mathrm{N}, 5.17497^{\circ} \mathrm{W}\right.$, in $16 \mathrm{~m}$ water depth, $1.4 \mathrm{~km}$ west of Perranporth), with all four sites exposed to similar energetic offshore wave conditions (Poate et al., 2009). The breaking wave height $\left(H_{b}\right)$ was estimated using the simple equation proposed by Komar and Gaughan (1972), where:

$$
H_{b}=0.39 g^{1 / 5}\left(T_{p} H_{s}^{2}\right)^{2 / 5}
$$

Here, $g$ is the acceleration due to gravity $\left(9.82 \mathrm{~ms}^{-2}\right) . T_{p}$ is the peak wave period (s) and $H_{s}$ the significant wave height $(\mathrm{m})$, which both came from the wave buoy.

\section{Results}

\subsection{Observed Temporal variations in Surface Grain Characteristics (Size, Sorting and}

\section{Distributions)}

In order to investigate the overall temporal variation in grain size, the $\mathrm{D}_{50}$ values from the same month at each site were averaged together to give the typical annual variation in grain size at each site (Figure 2). There is a clear seasonal cycle with the finest sediments typically present in the summer months (June to September) and the coarsest in the winter months (January to February), commensurate with persistent periods of low steepness swell waves and high-steepness storm waves respectively.

To investigate this in more detail, Figure 3 shows all the monthly sediment grain sizes and sorting values at one site (Perranporth) plotted as time-series with the breaking wave height. The Perranporth grain size samples had a mean of $0.33 \mathrm{~mm}$ and were moderately to moderately well sorted. The overall cyclic seasonal pattern is punctuated shorter-term fluctuations. The most extreme of these fluctuations is the extreme coarsening (grain sizes up to $0.6 \mathrm{~mm}$ ) and better sorting associated with the extreme storm waves of January / February 2014. Extended calm periods (e.g. June- 
Nov 2012) were typified by finer grain sizes $(0.28-0.29 \mathrm{~mm})$ and a poorer than average sorting.

At Porthtowan (Figure 4), the mean grain size is slightly coarser $(0.36 \mathrm{~mm})$ and the sediments are slightly better sorted (moderately well to well sorted), but a similar pattern was observed. Again there was a very well sorted coarse excursion related to the extremes storms of January / February 2014, and a finer and more poorly sorted than average associated with the June-November 2012 calm period.

To compare the grain size distributions observed under persistent large waves and persistent small waves, Figure 5 was plotted. Here, high wave energy and low wave energy conditions were defined as the upper and lower $30 \%$ of the total time-series, (corresponding to waves above $3.4 \mathrm{~m}$ being 'high energy' and waves below $0.8 \mathrm{~m}$ being 'low energy'). By combining all of the grain size distributions during occurrences of high and low wave energy conditions, it is clear that the fine (coarse) fractions increased in relative abundance at all four sites during prolonged periods of low (high) wave energy.

\subsection{A Model for the Temporal Evolution of Sediment Size and Sorting}

Beach erosion and accretion have long been linked with variations in wave steepness, whereby high steepness storm waves promote offshore sediment transport and low steepness swell waves drive an onshore sediment movement, (Johnson, 1949; King and Williams, 1949). This cycling of sediment on and offshore is known as the winter-summer or storm-swell or bar-berm cycle. The steeper waves that control this cycle can be achieved by either a reduction in wave period, an increase in wave height or both. Dean (1973) went on to find that a dimensionless wave steepness parameter 
(the dimensionless fall velocity, $\mathrm{H} / \mathrm{w}_{\mathrm{s}} \mathrm{T}$, where $\mathrm{w}_{\mathrm{s}}$ is the sediment fall velocity) controlled the development of bar-berm morphology.

Wright et al. (1985) demonstrated that the temporal evolution in beach morphodynamic state could be modelled using disequilibrium stress in the dimensionless fall velocity, noting improved correlations with the introduction of an antecedent term. More recently, Davidson et al. (2013) presented a model for shoreline evolution based on similar disequilibrium concepts, showing that waves that are steeper than antecedent conditions lead simultaneously to shoreline erosion and more dissipative beach states. Stokes et al. (2015) successfully applied this model to predict the development of three-dimensional beach morphology.

Based on these works and the observations made by this study, the authors propose the following model for the temporal evolution of grain size and sorting:

$$
\begin{aligned}
& \frac{d D_{50}}{d t}=\alpha\left(S-S_{\phi}\right) \\
& \frac{d \psi}{d t}=-\beta\left(S-S_{\phi}\right)
\end{aligned}
$$

Here $D_{50}$ is the median grain size, $\psi$ the sediment sorting (degree of variance between individual clast sizes), $t$ is time and $S$ the new equilibrium conditions that the system is progressing towards, given by: $H_{b} / L_{\infty}$ (Kamphuis, 1991) where $H_{b}$ is the breaking wave height and $L_{\infty}$ the deep water wavelength $\left(L_{\infty}=g T_{p}^{2} / 2 \pi\right) . S_{\phi}$ is a temporally evolving weighted average of the antecedent wave steepness. Following Wright et al. (1985) and Davidson et al. (2013) the inclusion of the $S_{\phi}$ parameter recognises that the system has significant hysteresis in which future change is strongly dependent on antecedent conditions. $S_{\phi}$ is calculated by:

$$
S_{\phi}=\left[\sum_{i=1}^{2 \phi} 10^{-i / \phi}\right]^{-1} \sum_{i=1}^{2 \phi} S_{i} 10^{-1 / \phi}
$$

This weighting function (Equation 4) decays at a rate governed by $\phi$ and reaches $10 \%$ and $1 \%$ at $\phi$ and $2 \phi$ days prior to the current calculation time. $\alpha, \beta$ and $\phi$ are model free 
parameters, where $\alpha$ controls the rate of change and magnitude of grain size variability and has units of $(\mathrm{m} / \mathrm{s})$ and $\beta\left(\mathrm{s}^{-1}\right)$ controls the rate and magnitude of changes in sorting. As sediment sorting is dimensionless, here the response rate parameter $(\beta)$ has units of $\mathrm{s}^{-1}$ and is negative due to the inverse relationship to grain size. $\phi$ controls the dominant period of variability (e.g. storm or seasonal) and has units of days. For large values of $\phi\left(\approx 10^{3}\right.$ days $) S_{\phi}$ converges on the time-series mean value and the model behaviour is dominated by seasonal and interannual variability. For values of $<10^{2}$ days storm frequency responses become significant (Davidson et al., 2013).

The model was calibrated by numerical integration of equations (2) - (4) with respect to time and then conducting a least-squares fit between the grain size and sorting time-series and the time integrated disequilibrium wave steepness (r.h.s. of Equations 2 and 3). The model skill was assessed using the least squares correlation coefficient $r^{2}$, which was iterated for successive values of $\phi$ in the range 5-10 ${ }^{3}$ days. Values of $\alpha$ and $\phi$ corresponding to maximum $r^{2}$-values were selected as the optimised model calibration coefficients, with the model calibrated using the initial $50 \%$ of the grain-size time series from Perranporth, Porthtowan and Chapel Porth, and model performance validated by comparisons with the remaining $50 \%$ of the unseen grain size record at these three sites. Gwithian is completely unseen and was used to assess the model skill on a site outside of the calibration set.

Figure 6 shows correlations between sediment grain size and sorting with various wave parameters. There were no significant correlations between grain size or sorting and either wave height (grain size $-\mathrm{A}, r^{2}=0.18, p=0.97$ and sorting $-\mathrm{B}, r^{2}=0.11$, $p=0.55$ ), antecedent wave height (grain Size $-\mathrm{C}, r^{2}=0.50, p=0.47$ and sorting $-\mathrm{D}$, $r^{2}=0.25, p=0.79$ ), and wave steepness (grain size $-\mathrm{E}, r^{2}=0.39, p=0.37$ and sorting $-\mathrm{F}$, $r^{2}=0.35, p=0.63$ ). However, model predictions (Equations 2 and 3) using the 
disequilibrium between an antecedent and instantaneous wave steepness time series, were highly significant for both grain size (Figure $6 \mathrm{G}, r^{2}=0.86, p<0.01$ ) and sorting (Figure $6 \mathrm{H}, r^{2}=0.75, p<0.05$ ).

The observed grain size change and the corresponding model predictions (equation 2) are shown in Figure 7 for Perranporth, Porthtowan and Chapel Porth. The unseen model validations comparisons with data are highly significant (Perranporth $r^{2}=0.96$, $p<0.01$, Porthtowan $r^{2}=0.77, p<0.05$ and Chapel Porth $\left.r^{2}=0.9, p<0.01\right)$. The model skilfully captures the observed seasonal succession in grain size, from finer summer to coarser winter values. The episodic storm responses are also modelled accurately.

The extreme UK winter storms of 2013-14 provided some of the largest wave heights and wave periods on record for the South-West of England (Masselink et al., 2015) and exceeded the hydrodynamic and sedimentological conditions present in the calibration set, yet model predictions still followed the measurements. At Perranporth, a typical coarsening due to the steeper winter storm waves was by an average of 0.06 $\mathrm{mm}(12 \%)$ in the surficial sediments, with a corresponding $0.7(15 \%)$ increase in sorting. During a 6-week period from January 2014 to February 2014, surface grain sizes rapidly coarsened by $64 \%$ to $0.61 \mathrm{~mm}$ at Perranporth, exceeding the calibration set maximum of $0.39 \mathrm{~mm}$. However, model predictions for Perranporth (and Porthtowan) are still skilful, and are capable of explaining both the coarse storm excursion (model predictions January to February 2014, Perranporth $r^{2}=0.83, p<0.05$ Porthtowan $r^{2}=0.73, p<0.05$ ) and the subsequent recovery (model predictions March to August 2014, Perranporth $r^{2}=0.96, p<0.01$, Porthtowan $r^{2}=0.79, p<0.05$ ). Although the very coarse grain sizes are lacking from the calibration data set, model performance is still good, as the mechanism remains unchanged in that waves that are 
considerably steeper than the weighted antecedent conditions generate a coarsening of the surficial sediments. The persistently steep storm waves, which drove the extreme coarsening observed in the time-series, were an order of magnitude larger than the corresponding antecedent conditions.

The model results also provide a grain size estimate for the period between January 2011 and January 2012, where there are no observations made. Despite no primary data to control the modelled grain size evolution or to validate the predictions, the model is able to predict the series when measurements restart in February 2012.

In addition to grain size, predictions were also made for sorting, (Equation 3, Figure 8). The correlation between the prediction and observed time-series is again significant (total-time series $r^{2}=0.75, p<0.05$ ). Encouragingly, the validation data set had a greater correlation coefficient than the calibration data set. Sorting predictions correlated well with both the seasonal cyclicity where the finer summer sediments were poorer sorted than the coarser winter sediments and the storm variability, where the rapid coarsening signal was reflected by an equally rapid improvement in sorting.

\subsection{Model Validation}

Despite identical incident wave forcing driving model predictions at each site, the three sites exhibit different behaviour due to the variability in the model free parameters $(\alpha, \beta$ and $\phi)$, with a systematic variability at the three sites that appears to be correlated with $\mathrm{D}_{50}$. Although only based on only three locations, both of the response rate parameters ( $\alpha$ and $\beta$ ), decreased with increasing grain size, where:

$$
\begin{array}{ll}
\alpha=-0.21 D_{50}+0.47 & \left(r^{2}=0.76, p<0.01\right) \\
\beta=-5.5 D_{50}+2.6 & \left(r^{2}=0.89, p<0.01\right)
\end{array}
$$


Conversely, although the range in $\phi$ was small (54-71 days), values show a significant linear increase with grain size, where:

$$
\phi=160 D_{50}+0.63 \quad\left(r^{2}=0.94, p<0.05\right)
$$

Monthly grain size data from Gwithian (2006-2008) were treated as an unseen dataset, with the model free parameters $(\alpha, \beta$ and $\phi)$ that were calculated via equations 5, 6 and 7. Hydrodynamic forcing is the same as in previous calibration and validation iterations. Gwithian represents an unseen location that has a $\mathrm{D}_{50}$ finer (minimum 0.24 $\mathrm{mm}$, mean $0.3 \mathrm{~mm}$, maximum $0.36 \mathrm{~mm}$ ) than the finest grain sizes (Perranporth, minimum $0.29 \mathrm{~mm}$, mean $0.33 \mathrm{~mm}$, maximum $0.61 \mathrm{~mm}$ ), included in the calibration data set and uses model free parameters empirically calculated rather than derived through model training. Despite this, predictions for both grain size and sorting (Figure 9) are still highly significant $\left(\mathrm{D}_{50}: r^{2}=0.86, p=0.05\right.$, Sorting: $\left.r^{2}=0.8, p=0.09\right)$.

\section{Discussion}

The model results indicate that disequilibrium stress in a wave steepness timeseries is suitable for predicting changes in shoreface grain size and sorting, with the predictions for the unseen location showing that calibration data sets from neighbouring sites can be used to efficiently predict both grain size and sorting for sites where there is no long-term record. Model predictions are still skilful during the extreme storm periods, where the waves are outside the parameter space of the calibration dataset.

The values of $\phi$ for this site are consistent with the observations by Splinter et al. (2015), with values of $\phi$ in the range of 50-100 days typifying beaches at the dissipative extreme of the intermediate beach state continuum (Wright and Short, 1984). This is consistent with the observed morphology at the four sites studied here, 
and is also characteristic of beaches that exhibit significant storm erosion during high steepness conditions, and a slower recovery during low steepness swells. Although the mean sampling frequency was 26 days, following the observations of Splinter et al. (2013), this was deemed sufficient to capture both the seasonal and storm variability without introducing significant aliasing.

The four sites included in this study have similar grain size distributions with an increase in the relative abundance of the finer fractions and a corresponding poor sorting due to the broader grain size distributions during persistent low-steepness antecedent conditions. When the incident waves become steeper, this fine fraction is rapidly removed from the shoreface generating significant bed level erosion and coarsening. The magnitude of temporal variability observed in grain size for both fair weather low-steepness swell and high steepness storm conditions is consistent with prior but shorter term studies with Buscombe et al. (2014) noticing a $40 \%$ cyclic variation linked to changes in the hydrodynamic conditions and Lee et al. (1998) noticing a rapid coarsening of the beach during extreme wave events.

The persistent high steepness conditions were responsible for bed level erosion and lowering of the shoreface, exposing the buried sediments present at depth. These buried sediments were significantly coarser than those at surface (Figure 10), and where equivalent in grain size to samples made following persistent high steepness conditions. The exposure of these buried sediments contributes to the coarsening grain size signals at the shoreface. Conversely bed level accretion was synonymous with the return of the fine material.

\section{Conclusions}


A data-set of 6 years of monthly sediment samples from four macro-tidal, energetic, sandy beaches were used to quantify changes in surface grain size and sorting.

Grain size and sorting showed a periodicity, with coarser, better-sorted surface sediments in the stormier winter months and finer, less well-sorted sediments in the calmer summer months. This succession was deterministically related to the disequilibrium in incident wave steepness. Peak surface grain sizes and sorting occurred when the current conditions were significantly and persistently steeper than a temporally averaged time series. Conversely, surface sediments became finer and less well sorted when the current conditions were persistently less steep than the weighted antecedent conditions.

A simple model is able to accurately capture the unseen variability in both surface grain size (average $r^{2}=0.86, p<0.01$ ) and sorting (average $r^{2}=0.75, p<0.05$ ) at all four beach sites, with skilful predictions of the seasonal signal and the irregular storm responses.

Model free parameters $(\alpha, \beta$ and $\phi)$ for each site were systematically related to the time-series median grain size. Model predictions for an unseen location with parameters empirically calculated were still highly skilful for both grain size $\left(r^{2}=0.86\right.$, $p=0.05)$ and sorting $\left(r^{2}=0.80, p=0.09\right)$.

\section{Acknowledgments}

This project was supported by a Plymouth University Maine Institute fieldwork grant to the Coastal Process Research Group at Plymouth University. Data is available by way of http://coastalprocesses.org. Special thanks to Tim Poate (2006-2008) and Christopher Stokes (2010-2013) for their efforts in the monthly data collection. 


\section{References}

Baptista, P., Coelho, C., Pereira, C., Bernardes, C. \& Veloso-Gomes, F. 2014. Beach morphology and shoreline evolution: Monitoring and modelling medium-term responses (Portuguese NW coast study site). Coastal Engineering, 84, 23-37.

Buscombe, D., Rubin, D. M., Lacy, J. R., Storlazzi, C. D., Hatcher, G., Chezar, H., Wyland, R. \& Sherwood, C. R. 2014. Autonomous bed-sediment imagingsystems for revealing temporal variability of grain size. Limnology and Oceanography: Methods, 12, 390-406.

Curran, J. C., Waters, K. A. \& Cannatelli, K. M. 2015. Real time measurements of sediment transport and bed morphology during channel altering flow and sediment transport events. Geomorphology, 244, 169-179.

Davidson, M. A., Splinter, K. D. \& Turner, I. L. 2013. A simple equilibrium model for predicting shoreline change. Coastal Engineering, 73, 191-202.

De Santiago, I., Morichon, D., Abadie, S., Castelle, B., Liria, P. \& Epelde, I. 2013. Video monitoring nearshore sandbar morphodynamics on a partially engineered embayed beach. 12th International Coastal Symposium (ICS). 458-463.

Dean, R. G. 1973. Heuristic models of sand transport in the surf zone. First Australian Conference on Coastal Engineering. Institution of Engineers, Australia, 209214.

Ferguson, R. \& Church, M. 2004. A simple universal equation for grain settling velocity. Journal of sedimentary Research, 74, 933-937.

Folk, R. L. 1966. A Review of Grain Size Parameters. Sedimentology, 6, 73-93.

Folk, R. L. \& Ward, W. C. 1957. Brazos River bar: a study in the significance of grain size parameters. Journal of Sedimentary Research, 27, 3-26.

Gallagher, E. L., Macmahan, J., Reniers, A., Brown, J. \& Thornton, E. B. 2011. Grain size variability on a rip-channeled beach. Marine Geology, 287, 43-53.

Gujar, A. R., Ganesan, P., Iyer, S. D., Gaonkar, S. S., Ambre, N. V., Loveson, V. J. \& Mislankar, P. G. 2011. Influence of morphodynamic variability over seasonal beach sediments and its probable effect on coastal development. Ocean \& Coastal Management, 54, 514-523.

Hanson, H. \& Kraus, N. C. 1989. GENESIS: Generalized Model for Simulating Shoreline Change. Report 1. Technical Reference. DTIC Document.

Holland, K. T. \& Elmore, P. A. 2008. A review of heterogeneous sediments in coastal environments. Earth-Science Reviews, 89, 116-134.

Kamphuis, J. W. 1991. Alongshore sediment transport rate. Journal of Waterway, Port, Coastal, and Ocean Engineering, 117, 624-640.

Komar, P. D. \& Gaughan, M. K. 1972. Airy wave theory and breaker height prediction. Coastal Engineering Proceedings, 1.

Larson, M. \& Kraus, N. C. 1995. Prediction of cross-shore sediment transport at different spatial and temporal scales. Marine Geology, 126, 111-127.

Lee, G.-H., Nicholls, R. J. \& Birkemeier, W. A. 1998. Storm-driven variability of the beach-nearshore profile at Duck, North Carolina, USA, 1981-1991. Marine Geology, 148, 163-177.

Masselink, G., Evans, D., Hughes, M. G. \& Russell, P. 2005. Suspended sediment transport in the swash zone of a dissipative beach. Marine Geology, 216, 169189.

Masselink, G. \& Pattiaratchi, C. 2001. Seasonal changes in beach morphology along the sheltered coastline of Perth, Western Australia. Marine Geology, 172, 243263. 
Masselink, G. \& Russell, P. 2006. Flow velocities, sediment transport and morphological change in the swash zone of two contrasting beaches. Marine Geology, 227, 227-240.

Masselink, G., Scott, T., Poate, T., Russell, P., Davidson, M. \& Conley, D. 2015. The extreme 2013/2014 winter storms: hydrodynamic forcing and coastal response along the southwest coast of England. Earth Surface Processes and Landforms [Online]. Available: http://dx.doi.org/10.1002/esp.3836.

Masselink, G. \& Short, A. D. 1993. The Effect of Tide Range on Beach Morphodynamics abd Morphology: A Conceptual Beach Model. Journal of Coastal Research, 9, 785-800.

Mclaren, P. \& Bowles, D. 1985. The effects of sediment transport on grain-size distributions. Journal of Sedimentary Research, 55, 457-470.

Mclean, R. F. \& Kirk, R. M. 1969. Relationships between grain size, size-sorting, and foreshore slope on mixed sand - shingle beaches. New Zealand Journal of Geology and Geophysics, 12, 138-155.

Nielsen, P. 2002. Shear stress and sediment transport calculations for swash zone modelling. Coastal Engineering, 45, 53-60.

Poate, T., Kingston, K., Masselink, G. \& Russell, P. 2009. Response of High-energy, Macrotidal Beaches to Seasonal Changes in Wave Conditions: Examples from North Cornwall, UK. Proceedings of the 10th International Coastal Symposium (ICS). Journal of Coastal Research, 747-751.

Roelvink, D., Reniers, A., Van Dongeren, A., Van Thiel De Vries, J., Lescinski, J. \& Mccall, R. 2010. XBeach model description and manual. Unesco-IHE Institute for Water Education, Deltares and Delft University of Tecnhology. Report June, 21, 2010.

Scott, T., Masselink, G. \& Russell, P. 2011. Morphodynamic characteristics and classification of beaches in England and Wales. Marine Geology, 286, 1-20.

Scott, T., Russell, P., Masselink, G. \& Wooler, A. 2009. Rip current variability and hazard along a macro-tidal coast. Journal of Coastal Research, 56, 895-898.

Sherman, D. J. \& Bauer, B. O. 1993. Dynamics of beach-dune systems. Progress in Physical Geography, 17, 413-447.

Splinter, K. D., Turner, I. L. \& Davidson, M. A. 2013. How much data is enough? The importance of morphological sampling interval and duration for calibration of empirical shoreline models. Coastal Engineering, 77, 14-27.

Splinter, K. D., Turner, I. L. \& Davidson, M. A. 2015. A Multi-site Analysis of Equilibrium Shoreline Change: Linking Model Free Parameters to Environmental Variables. Journal Of Geophysical Reserach, ACCEPTED.

Stokes, C., Davidson, M. \& Russell, P. 2015. Observation and prediction of threedimensional morphology at a high-energy macrotidal beach. Geomorphology, 243, 1-13.

Turki, I., Medina, R., Coco, G. \& Gonzalez, M. 2013. An equilibrium model to predict shoreline rotation of pocket beaches. Marine Geology, 346, 220-232.

Villaret, C., Hervouet, J.-M., Kopmann, R., Merkel, U. \& Davies, A. G. 2013. Morphodynamic modeling using the Telemac finite-element system. Computers \& Geosciences, 53, 105-113.

Wal, A. \& Mcmanus, J. 1993. Wind regime and sand transport on a coastal beach-dune complex, Tentsmuir, eastern Scotland. Geological Society, London, Special Publications, 72, 159-171.

Wright, L. D. \& Short, A. D. 1984. Morphodynamic variability of surf zones and beaches: A synthesis. Marine Geology, 56, 93-118. 
Wright, L. D., Short, A. D. \& Green, M. O. 1985. Short-term changes in the morphodynamic states of beaches and surf zones: An empirical predictive model. Marine Geology, 62, 339-364.

Yang, C., Jiang, C. \& Lin, B. 2013. Modelling Graded Sediment Transport and Bed Evolution in a Tidal Harbour. Journal of Coastal Research, 29, 736-744. 
Figure 1. Left) The location of the four study sites on the Northwest coast of Cornwall (UK) and the nearshore wave buoy, $1 \mathrm{~km}$ offshore from Perranporth in $\sim 16 \mathrm{~m}$ water depth.

A Centre) Panoramic photo of each site taken from the south looking north, green circle denotes the mid-tide sediment sampling point.

Right) Mean alongshore-averaged profile plots from each site. Cross-shore distance increases in the offshore direction.

Figure 2. Monthly ensemble average grain size for Perranporth (2008-2015), Porthtowan (2008-2015), Chappelporth (2008-2011) and Gwithian (2008-2011).

Figure 3. Time-series of Perranporth sediment grain size and sorting (smaller values equals better sorted). Each data point is a mean of a settling tube analysis of 5 separate subsamples with error bars representing the standard deviation of these 5 runs.

Figure 4. Time-series of Porthtowan sediment grain size and sorting (smaller values equals better sorted). Each data point is a mean of a settling tube analysis of 5 separate subsamples with error bars representing the standard deviation of these 5 runs.

Figure 5. Ensemble average grain size distributions for the four study sites in high (upper 30\% of time-series) and low (lower 30\% of time-series) energy conditions.

Figure 6. The correlation between monthly grain size at Perranporth (Red), Porthtowan (Blue), Chapel Porth (White), Gwithian (Green) and various forcing conditions, with wave height (A and $\mathrm{B})$, antecedent wave height ( $\mathrm{C}$ and $\mathrm{D})$ and wave steepness (E and $\mathrm{F}$ ) all showing no significant correlation to grain size. Conversely model predictions using the disequilibrium in instantaneous and antecedent wave steepness were highly significant (Grain size, G, $r^{2}=0.86$. Sorting, $\mathrm{H}, r^{2}=0.75$ )

Figure 7. The temporal evolution of grain size and corresponding model predictions at A) Perranporth (total time series $\left.r^{2}=0.96\right)$, B) Porthtowan $\left(r^{2}=0.77\right)$ and C) Chapel Porth $\left(r^{2}=\right.$ 0.9). Also shown are the model free parameters for each site. Note that model predictions are available for 2011 where sediment sampling did not occur.

The initial 50\% of each time series (blue triangles) was used to calibrate the model, whereas the latter half (green triangles) was unseen, and used as a validation.

Figure 8. The temporal evolution of sorting and corresponding model predictions at A) Perranporth (total time series $\left.r^{2}=0.91\right)$, B) Porthtowan $\left(r^{2}=0.83\right)$ and C) Chapel Porth $\left(r^{2}=\right.$ 0.78). Also shown are the model free parameters for each site. Note that model predictions are available for 2011 where sediment sampling did not occur.

Figure 9. Time series of sediment grain size (top) and sorting (bottom) for Gwithian, with corresponding model predictions (Grain size $r^{2}=0.86$, Sorting $r^{2}=0.8$ ). Gwithian is unseen by the model, with model free parameters empirically calculated from equations 5, 6 and 7 .

Figure 10. The sediment size present at depth for the mid tide sampling location at Perranporth. The black line represents a sand core collected on 08/11/2014 and the solid red line a core collected on 23/01/2015 after beach erosion. The dashed red line shows the surface bed level when the core was taken. 
Figure 1
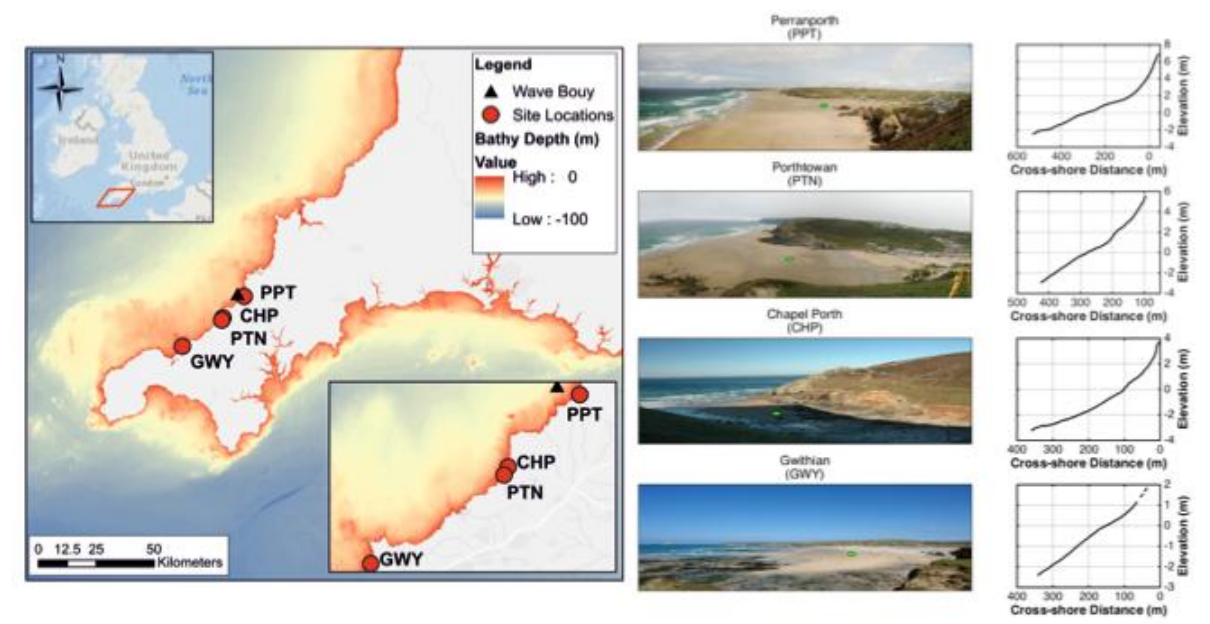


\section{Figure 2}
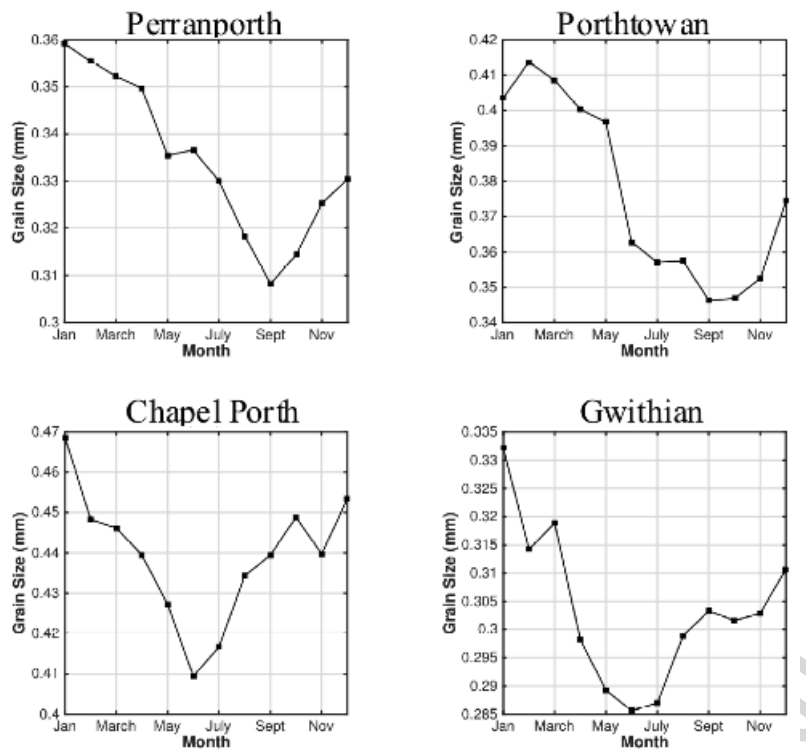
Figure 3

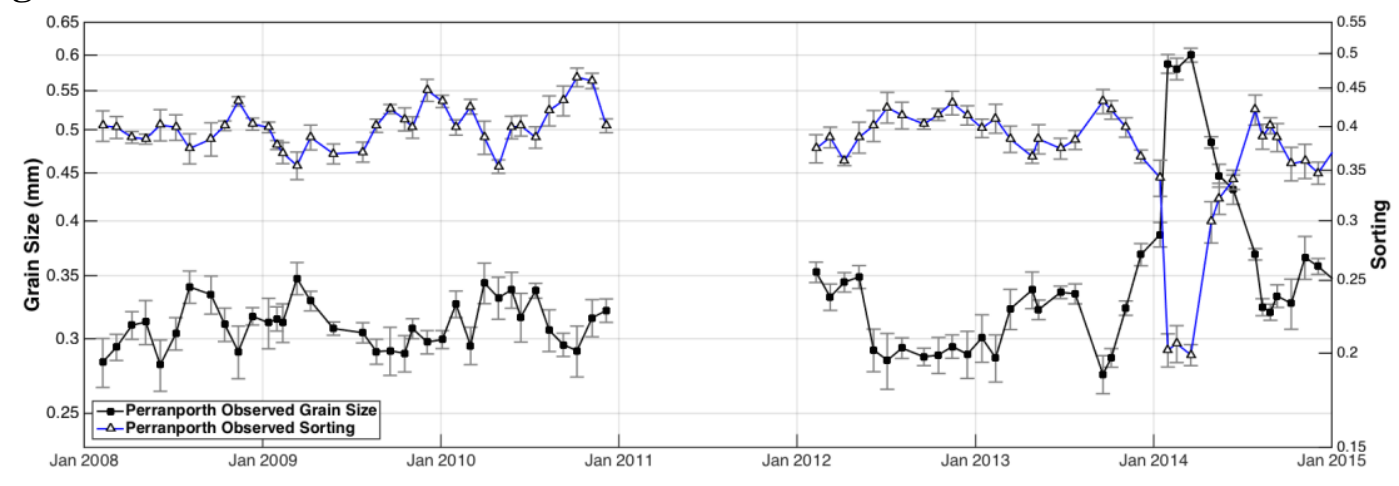


Figure 4

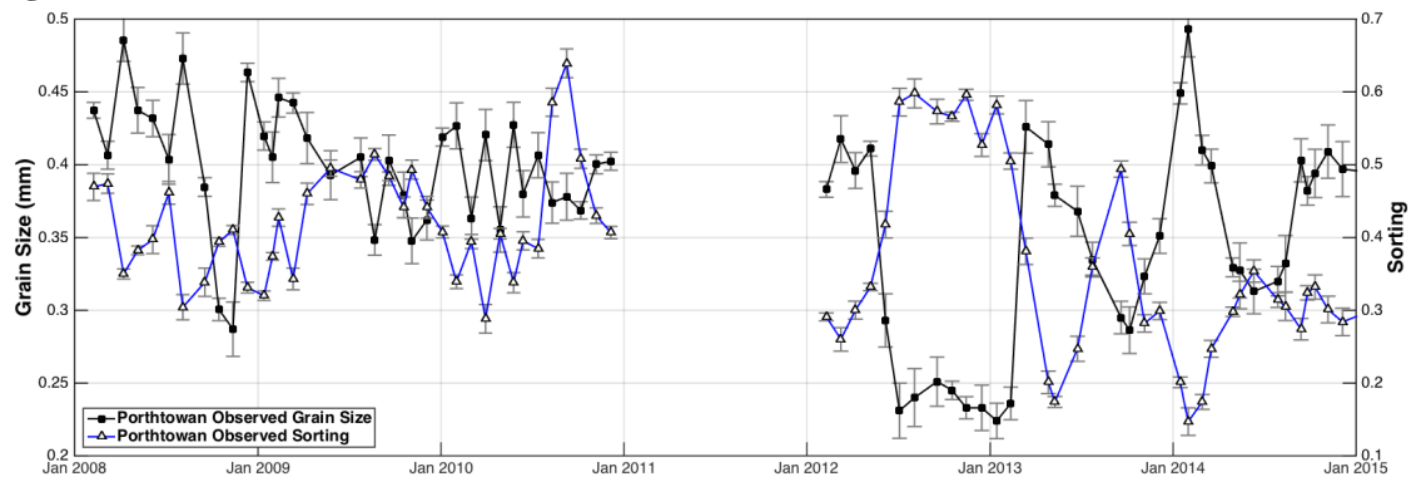




\section{Figure 5}
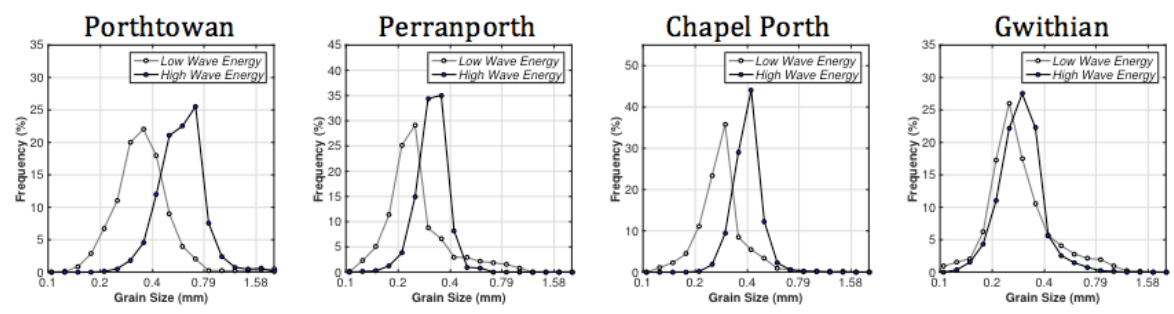
Figure 6

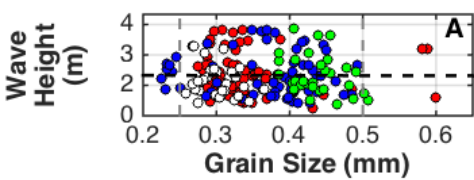

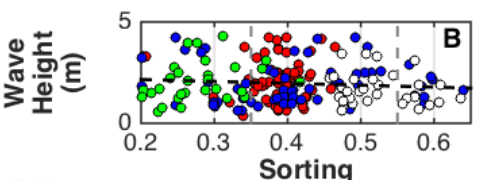
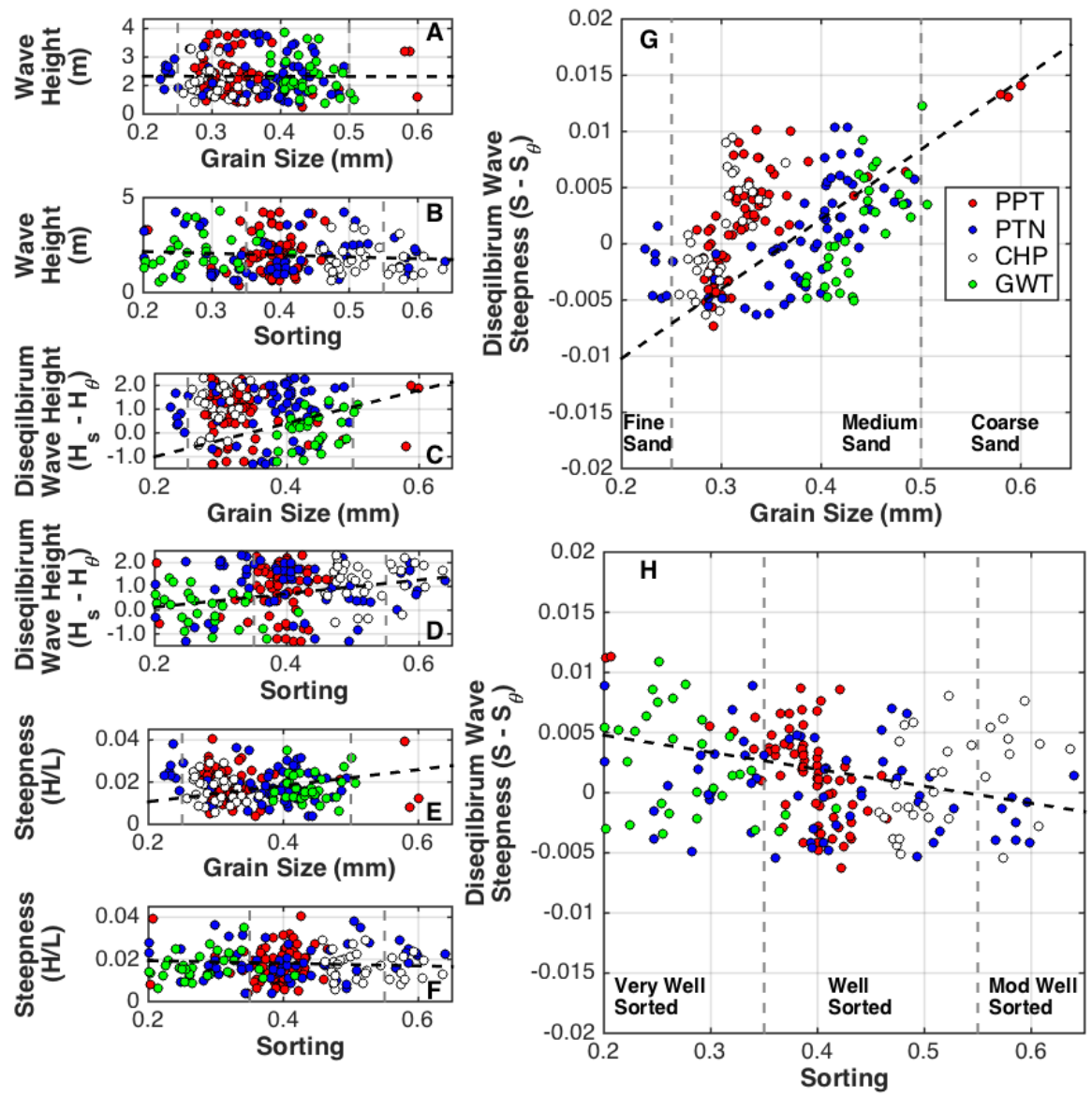
Figure 7
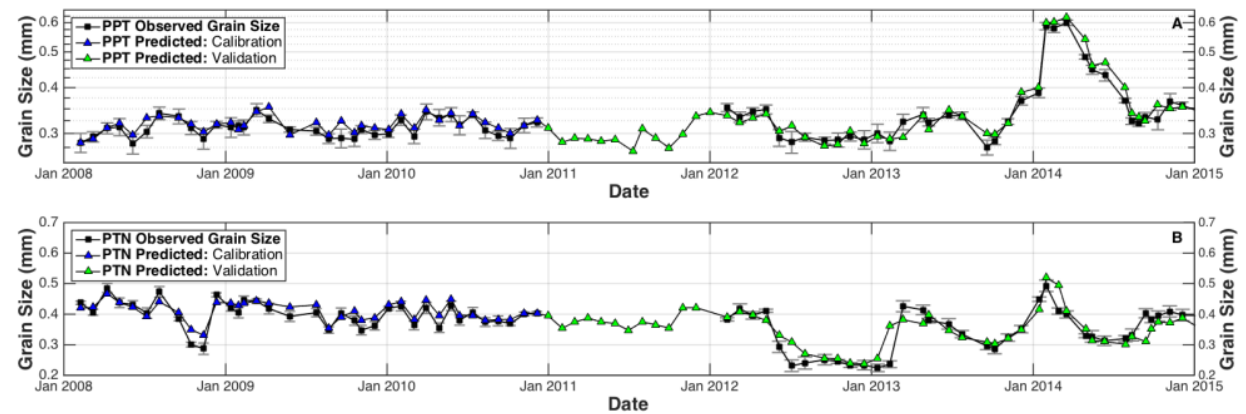

Jan 2009

\begin{tabular}{|ccc|}
\hline Site & $\alpha$ & $\phi$ \\
\hline Perranporth & 0.41 & 54 \\
Porthtowan & 0.4 & 60 \\
Chapel Porth & 0.39 & 71 \\
\hline
\end{tabular}

\begin{tabular}{ll} 
Chapel Porth & 0.39 \\
\hline
\end{tabular} 
Figure 8
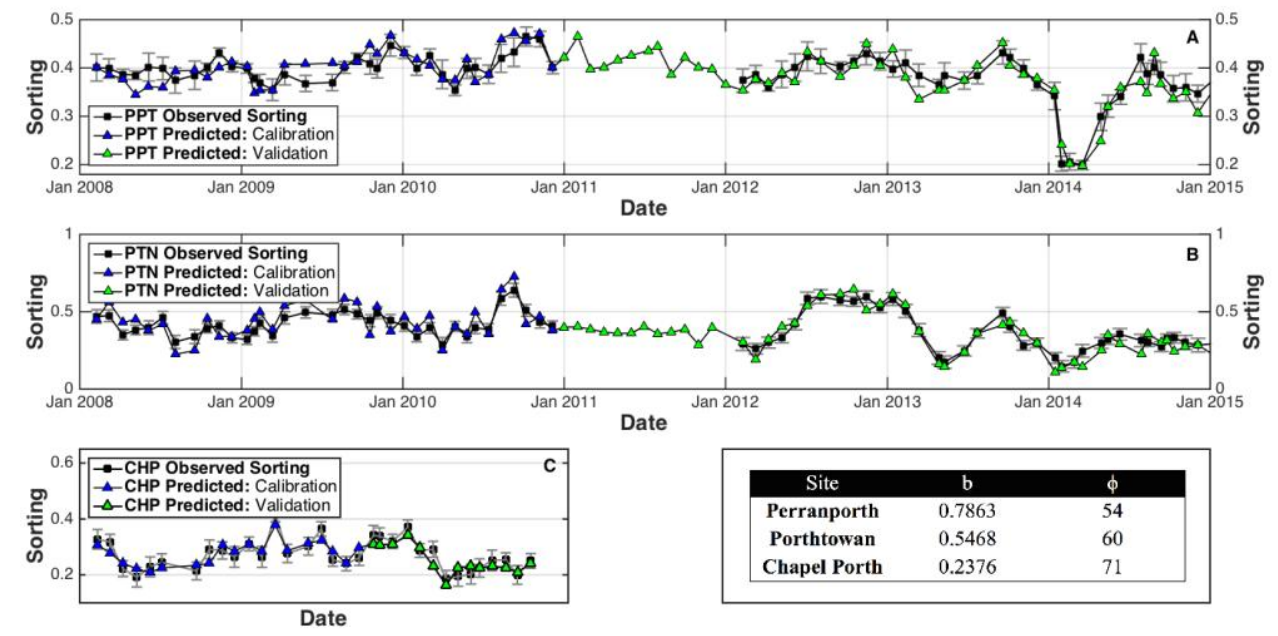
Figure 9
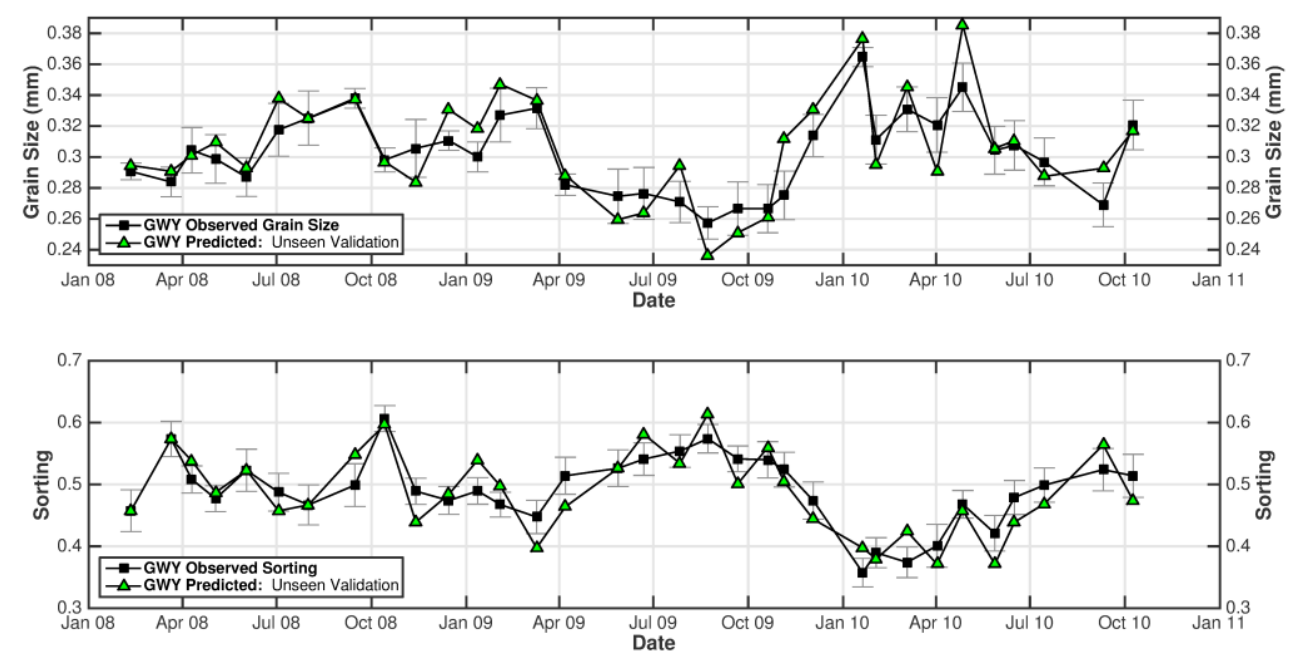
Figure 10

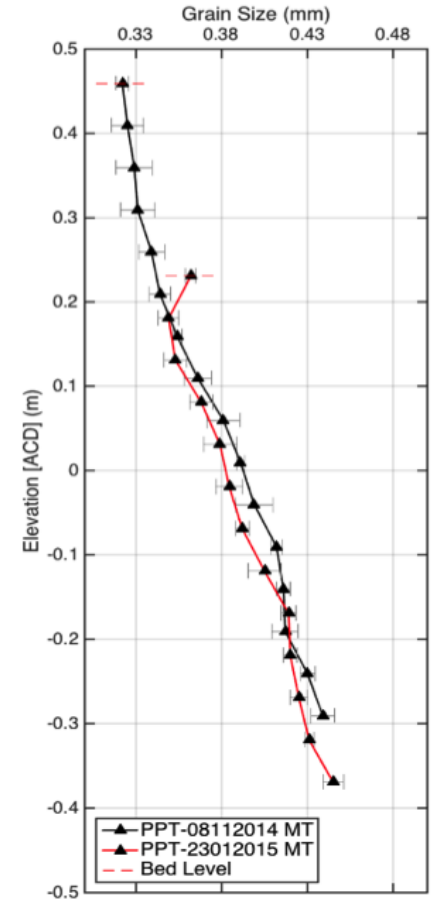




\section{Highlights}

- Surface grain size at four energetic, macro-tidal beaches showed a significant periodicity.

- Temporal changes were coherently linked to the disequilibrium in wave steepness.

- A model that accurately captures the variability in grain size and sorting is proposed 